\title{
O DEVER DE CONTRATAÇÃO DE TRABALHADORES COM DEFICIÊNCIA E O PRINCÍPIO DA IGUALDADE
}

\author{
THE DUTY OF HIRE WORKES WITH DISABILITIES AND THE PRINCIPLE OF \\ EQUALITY
}

\author{
${ }^{1}$ Veronica Calado \\ ${ }^{2}$ Flávio Augusto de Oliveira Santos
}

\section{RESUMO}

A partir da entrada em vigor do artigo 93 da Lei 8.213/1991 passou a ser juridicamente exigível a contratação de trabalhadores com deficiência nas empresas com 100 (cem) ou mais empregados. Estatisticamente demonstra-se que apesar da eficácia técnica tal norma, ainda hoje, padece de ineficácia social. O presente artigo analisa em que medida é possível extrair do princípio da igualdade o reconhecimento da imposição de um dever jurídico de contratação de trabalhadores com deficiência por parte das empresas que não estejam juridicamente obrigadas ao cumprimento do artigo 93 Lei 8.213/1991. A pesquisa foi desenvolvida em conformidade com o método dedutivo.

Palavras-chave: Inclusão social; Trabalhadores com Deficiência; Ação Afirmativa; Dever de contratação; Igualdade Material.

\begin{abstract}
From the validity of the article 93 of the Law 8.213/1991, it became legally enforceable to obligate the hiring of workers with disabilities in companies with 100 (one hundred) or more employees. Statistically it is shown that despite technical efficacy, this norm still suffers from social inefficiency. This article examines the extent to which it is possible to extract from the principle of equality the recognition of the imposition of a legal duty to hire disabled workers by companies that are not legally obliged to comply with article 93 of the Law 8,133/1991. The research was developed in accordance with the deductive method.
\end{abstract}

Keywords: Social inclusion; Workers with Disabilities; Affirmative Action; Duties of contracting; Equality Material.

\footnotetext{
${ }^{1}$ Mestranda em Direito Empresarial e Cidadania pelo Centro Universitário Curitiba (UNICURITIBA), Curitiba, Paraná,Brasil. Integrante dos grupos de pesquisa "Tutela Jurídica do Trabalhador com Deficiência" e "Intervenção do Estado e da Administração Pública no Domínio Econômico e Social. Email: vero_calado@ hotmail.com

${ }^{2}$ Mestrando em Direito Empresarial e Cidadania pelo Centro Universitário Curitiba (UNICURITIBA), Curitiba, Paraná,Brasil. Integrante do grupo de pesquisa "Intervenção do Estado e da Administração Pública no Domínio Econômico e Social: Políticas Públicas com vistas à promoção do desenvolvimento nacional sustentável (da sanção punitiva à sanção premial)". Email: flavio2501@ hotmail.com
} 


\section{INTRODUÇÃO}

Embora a Constituição da República Federativa do Brasil (CRFB) assente a igualdade entre os seus princípios fundamentais, dentro do contexto das sociedades contemporâneas não faltam exemplos de que tanto a liberdade de oportunidades, quanto a igualdade de acesso às instituições não estão sendo isonomicamente concedidas. Vale dizer, diante da diversidade, marca da sociedade contemporânea, não raramente assistimos à perpetuação de situações discriminatórias contra os mais variados grupos. Com as pessoas com deficiência, infelizmente, não se passa de forma diversa.

O artigo 93 da Lei 8.213/1991 (RPS) é ação afirmativa que tem por finalidade auxiliar no processo de inclusão de trabalhadores com deficiência ou de trabalhadores reabilitados pela Previdência Social no mercado formal de trabalho brasileiro, na medida em que impõe às empresas com 100 (cem) ou mais empregados o dever jurídico de reservar cotas para esses trabalhadores na proporção de $2 \%$ a $5 \%$ (dois a cinco por cento) proporcionalmente em relação ao número total de empregados na empresa. No entanto, passados aproximadamente 25 (vinte e cinco) anos da entrada em vigor desta regra, ainda hoje, sua eficácia social pode ser questionada, vez que dados do IBGE demonstram que, comparativamente, o número de pessoas com deficiência ainda é muito inferior ao número de trabalhadores que não apresentam quaisquer formas limitações dentro do âmbito do mercado de trabalho.

Ora, se a intenção do legislador ao momento da positivação de tal norma foi a de tentar promover a igualdade, a situação fática, tal como exposta, não nos deixa duvidar de que o objetivo almejado ainda não foi, sequer razoavelmente, alcançado. Muito há que ser feito para que este cenário social possa ser positivamente alterado. Não há dúvidas de que medidas devem ser tomadas para corrigir esta situação, especialmente se considerarmos o fato de que a CRFB aponta dignidade da pessoa humana (art. $1^{\circ}$, inc. III) ao lado da valorização do trabalho e da livre iniciativa (art. 1, inc. IV) entre os fundamentos da República Federativa do Brasil. Não sendo possível ignorar a existência de uma função social da propriedade, e consequentemente da empresa, a qual lhe é expressão máxima, por força do art. 170, inc. III.

Busca-se com o presente artigo responder ao seguinte questionamento: em que medida o princípio igualdade (ou isonomia) impõe aos empregadores que não são legalmente 
obrigados ao cumprimento do artigo 93 da RPS o dever jurídico de contratação de trabalhadores com deficiência?

Para a elaboração do presente artigo foi utilizado o método dedutivo de pesquisa.

\section{O PRINCÍPIO DA IGUALDADE E A RECEPÇÃO DAS AÇÕES AFIRMATIVAS NO ORDENAMENTO JURÍDICO BRASILEIRO}

Segundo a Teoria dos Direitos Fundamentais proposta por Robert Alexy um dos pontos centrais no que diz respeito à diferenciação entre regras e princípios reside na constatação de que estes seriam espécies de normas que "ordenam que algo seja realizado na maior medida possível dentro das possibilidades fáticas e jurídicas existentes”, ou seja, seriam mandamentos de otimização dentro do ordenamento, enquanto aquelas seriam "normas que são sempre satisfeitas ou não satisfeitas" (ALEXY, 2006, p. 90).

A igualdade, na medida em que integra o rol de princípios constitucionalmente assegurados, atuaria no ordenamento jurídico brasileiro, de acordo com esta teoria, como um mandado de otimização, realizável em diferentes graus. Logo, e porque goza do status normativo de princípio, é algo a ser realizado na maior medida possível, observadas as possibilidades fáticas e jurídicas diante do caso concreto, devendo se vincular tanto a elaboração, quanto a aplicação das leis (SZUPSZYNSKI, 2014, p. 27-28).

A proibição da discriminação - que, de um lado, significa adoção do princípio da vedação da desigualdade, de outro, aponta para a invalidade do comportamento que venha a ser motivado por preconceito ou discriminação constitucionalmente injustificável - por sua vez, não vem promovendo, por si só, a equiparação social inicialmente idealizada pelo constituinte. Vale dizer, em grande parte das situações, o tratamento formalmente igualitário, por ser um princípio completamente despojado de mecanismos hábeis para lhe conceder qualquer efetivação prática, acaba constituindo mero mecanismo de manutenção de status quo, e não de alteração social tal como vem se exigindo mais contemporaneamente (ROCHA, 1996, p. 284).

\subsection{O CONTEÚDO JURÍDICO DO PRINCÍPIO DA IGUALDADE}

Segundo os ensinamentos de Celso Antônio BANDEIRA DE MELLO (1995, p. 914), o conteúdo político-ideológico do princípio da igualdade historicamente nos direcionou para acreditarmos e, consequentemente defendermos, que a lei não pode exercer quaisquer 
privilégios ou impor perseguições em relação a determinados grupos, sob pena de caracterização de flagrante incompatibilidade com o princípio em análise. Por outro lado, já mencionamos que o ordenamento jurídico brasileiro, a exemplo de outros tantos, apesar de dar mais ênfase à igualdade formal, vem admitindo a legitimidade de algumas desigualdades notadamente quando o bem comum assim o justificar.

A ideia de tratamento igual aos "iguais" e desigual aos desiguais na medida de suas desigualdades - ideal de equidade proposto por Aristóteles, e, anos mais tarde, reforçado por Rui Barbosa - traz a esta discussão uma questão fundamental, qual seja: mas, afinal, quem são os iguais e, consequentemente, sobre quem deve recair o rótulo de desigual? Mais do que isso, faz-se necessário verificar se há um critério legitimamente manipulável capaz de autorizar a distinção de pessoas e de situações em grupos apartados para fins de tratamento jurídico diverso.

A isonomia tem o condão de autorizar a adoção de algumas medidas de natureza “discriminatórias" sem que seja desnaturada. Isto só seria constitucionalmente possível quando a adoção do fator de discrímen atenda simultaneamente às seguintes condições: i) demonstração de um vínculo de correlação lógica abstrata entre a peculiaridade diferencial e a desigualdade no tratamento dispensado visando o atingimento de um interesse constitucionalmente assegurado; ii) que o fator de discrímen seja aferido de forma a que não venha a contrariar, formal ou materialmente, um determinado preceito normativo evitando-se a formação de tamanha singularização que obste a observância de seu preceito; iii) verificação de existência de uma correlação lógica entre fator de discrímen e a desequiparação procedida sob pena de invalidade do preceito; iv) existência de consonância entre a discriminação perpetrada e os interesses constitucionalmente protegidos, e assim que a desequiparação possa vir a atingir mais de um indivíduo (ou seja, não há como se sustentar que a discriminação venha a ser direcionada a um único destinatário); v) que exista distinção real entre as pessoas discriminadas; vi) a existência de correlação lógica entre os fatores diferenciais, bem como em relação ao regime jurídico aplicável em função de tal distinção, e, por fim, vii) que, in concreto, o vínculo de correlação supra referido seja pertinente em função dos interesses constitucionalmente protegidos (BANDEIRA DE MELLO, 1995, p. 21-43).

Não há dúvidas acerca da existência de mecanismos de "igualação" jurídica que, em um primeiro momento, possam aparentar a adoção de tratamento inconstitucionalmente desigual. Mas, quando bem observados é possível constatar que a inconstitucionalidade seja apenas aparente, porque justificada diante da constatação de é o Direito que traz a noção de 
que as desigualdades devam ser corrigidas, sob pena de não ser possível cogitar-se da igualdade (GONZAGA, 2009, p. 3-4).

\subsection{AS AÇÕES AFIRMATIVAS E O PARADIGMA CONSTITUCIONAL EMERGENTE DA IGUALDADE}

As ações afirmativas consistem em um legado do direito norte-americano (em especial dos Estados Unidos da América), país em que, a partir da década de 1960, se passou a buscar de forma institucionalizada a expansão do movimento pela ampliação de dos direitos civis de determinados grupos sociais minoritários, em especial através da realização da extensão da igualdade de oportunidades de trabalho aos cidadãos.

Resumidamente, pode-se dizer que tais ações surgiram quando da edição de uma ordem proveniente do Poder Executivo norte-americano, durante o mandato do Exmo. Sr. Presidente John F. Kennedy - a Executive Order 10.925/1961 - que, por sua vez, delineou a President's Comitee on Equal Employment Opportunity impondo, entre outras questões, a observância em todos os contratos celebrados com o governo federal de algumas questões relativas à não discriminação relativas à raça, cor, credo ou nacionalidade de candidatos a vagas ociosas ou ainda em relação aos funcionários já efetivados (MENEZES, 2001, p. 87$88)$.

Segundo lições de Joaquim BARBOSA (2001, p. 134), as ações afirmativas representaram um grande avanço para o que diz respeito ao contexto social norte-americano do período, vez que representam uma quebra paradigmática sem precedentes no país especificamente no que guarda relação com a postura estatal, porque impôs que esta deixasse de lado a tradicional postura de neutralidade para passar a ativamente colocar na balança fatores como sexo, idade, raça, cor e origem nacional, para, assim, começar um processo de redução do tratamento discriminatório.

Importante salientar que apesar da importância histórica do fato acima narrado é certo que ações afirmativas não se resumiram a esta única experiência. Outros países (no continente europeu, Índia, Austrália entre outros) também vivenciaram, respeitadas suas peculiaridades, esta nova forma de agir em prol da igualdade (MOEHLECKE, 2002, p. 198199). Sendo assim, o público alvo de ações afirmativas foi bastante diversificado ao longo dos anos e dos países que adotaram tais ideias. Foi possível observar grande diversidade no que 
diz respeito aos modelos de ações afirmativas adotados, sendo o sistema de reserva de cotas um dos mais emblemáticos.

Especificamente dentro do ordenamento jurídico brasileiro é o princípio da igualdade uma norma constitucionalmente assegurada, tendo sido positivado de forma contínua desde a Carta Imperial, de 1824 (ROCHA, 1996, p. 288). Todavia, tanto a Literatura quanto a História de nosso país demonstram que, ainda assim, preconceitos e a discriminação contra determinados grupos se mantiveram tão arraigados ao povo brasileiro, que ainda hoje podem ser constantemente observados em detalhes de nossa organização social, política e até mesmo cultural. Por isso, não parece estranho afirmar-se que mais contemporaneamente seja a igualdade, antes de uma prescrição normativa, um verdadeiro objetivo ou uma meta a ser alcançada. Para tanto, o constituinte de 1988 manteve o princípio da isonomia, mas concedendo-lhe nova roupagem, para assim permitir que as ações afirmativas passassem a merecer um lugar de destaque em nosso sistema legislativo.

O Direito, dentro deste contexto, passou a ser observado como um instrumento capaz de permitir o alcance da Democracia e da Justiça social. Tanto é verdade, que o Preâmbulo da CRFB, o qual mesmo não possuindo força normativa tem o condão de demonstrar em linhas gerais as intenções que permearam a criação do novo sistema jurídico nacional, afirmam com claridade solar a preocupação desta República Federativa no sentido de constituir um Estado Democrático de Direito. Como se vê, o desafio passa a ser o de assegurar o princípio da igualdade não apenas enquanto regra, mas sim como um valor.

Vale ressaltar, esta transformação paradigmática ensejou, entre outros tantos dispositivos, a elaboração do artigo $3^{\circ}$ CRFB, o qual enuncia um rol de verbos (comportamentos ativo) desejáveis para constituir a sociedade brasileira ideal. Os objetivos da República são, portanto, obrigações de cunho transformador dos quadros político e social, que, em última análise, pretendem traduzir as mudanças necessárias para que seja possível chegar à igualdade material.

Note-se, como bem observa Carmem Lúcia Antunes ROCHA (1996, p. 290), que se nos mantivéssemos como meros defensores da ideia de que a igualdade corresponderia apenas e tão somente à vedação do tratamento discriminatório, o princípio da isonomia permaneceria sendo insuficiente para o alcance das finalidades propostas. Em suma, as mudanças acerca de tudo o que se sedimentou histórica, política e socialmente no Brasil parece depender, em um primeiro momento, da adoção de determinados comportamento ativos, os quais podem 
contribuir para a transformação da realidade de exclusão social e desigualdades para grupos vulneráveis e/ou marginalizados, garantindo-lhes maior dignidade humana.

A ideia central dos objetivos insculpidos no art. $3^{\circ}$ da CRFB repise-se guardam intrínseca relação com a busca pela construção de uma nova sociedade, a qual deve se manter vinculada aos paradigmas emergentes de justiça social, igualdade e desenvolvimento nacional. E, as ações afirmativas como instrumentos de realização deste paradigma constitucional emergente ao apresentarem-se como medidas que se utilizam deliberadamente de "critérios raciais, étnicos ou sexuais com o propósito específico de beneficiar um grupo em situação de desvantagem prévia ou de exclusão, em virtude de sua respectiva condição racial, étnica ou sexual” (SZUPSZYNSKI, 2014, p.74), parecem contribuir de forma irrefutável com esse processo de correção das distorções comportamentais a que submetemos, de maneira reiterada, determinados grupos.

\section{A RESERVA DE COTAS PARA PESSOAS COM DEFICIÊNCIA}

No Brasil, um dos exemplos mais característicos de ação afirmativa consiste na adoção do modelo de cotas para pessoas com deficiência ou reabilitados da Previdência Social. Este modelo de reserva legal de oportunidades de trabalho busca realizar, em alguma medida, a inclusão de trabalhadores que possuem limitações (física, psíquica ou sensorial), recaindo tanto sobre as contratações do setor público, quanto da inciativa privada.

A necessidade de imposição de um dever jurídico de contratação de trabalhadores com deficiência parece se justificar diante da constatação de existência de comportamentos ou atitudes sociais que, infelizmente, ainda hoje mantém estigmas de preconceito sobre esse determinado grupo de cidadãos. Exemplo disso é o fato de que, ainda hoje, um grande número das pessoas (empregadores ou não) erroneamente acreditarem que as pessoas com deficiência apresentam limitações "insuperáveis" o que, segundo suas crenças os tornariam irremediavelmente inaptos ao trabalho formal. Outra situação comumente narrada pelos empregadores seria uma dificuldade no sentido de encontrar profissionais com deficiência capacitados, ainda que minimante, o que eles acreditam ser uma escusa justificável para a não contratação de tais profissionais e, o consequente descumprimento dos dispositivos legais que impõe a reserva de oportunidades de trabalho para pessoas com deficiência, ou como comumente denomina-se a "lei de cotas" (LARAIA, 2009, p. 143). 
A compulsoriedade de contratação de pessoas com deficiência para o preenchimento de vagas de trabalho no setor público foi inicialmente delimitada pelo artigo 37 , inc. VIII da CRFB. Segundo Carmen Lúcia Antunes ROCHA (1996, p. 292) o que se tem por esta regra “é a expressão ou a revelação do que se contém no princípio da igualdade jurídica, segundo a concepção dinâmica e positiva do constitucionalismo contemporâneo”. O percentual a ser reservado para pessoa com deficiência no setor público, por força da previsão contida no art. 37, $\$ 1^{\circ}$ do Decreto 3.298/1999, deve equivaler a, no mínimo, 5\% (cinco por cento) do total das vagas ofertadas no certame. Com fundamento neste regramento, a Lei 8.212/1990, especificamente em seu art. $5^{\circ} \S 2^{\circ}$, foi pioneira ao trazer previsão expressa no sentido de reservar vagas para trabalhadores com deficiência no serviço público federal da União, autarquias e fundações em âmbito federal. Vale dizer, tal dispositivo assegura às pessoas com deficiência o seu direito de inscrever-se em concursos públicos, desde que as atribuições sejam compatíveis com as limitações que o candidato apresente em percentual equivalente a $20 \%$ (vinte por cento) das vagas oferecidas no concurso.

O princípio da igualdade encontra-se intimamente relacionado com a reserva de cotas para pessoas com deficiência, na medida em que visa corrigir o cenário de exclusão do mercado de trabalho formal que dados estatísticos oficiais a seguir explorados demonstram. Assim, deverá a pessoa com deficiência participar do certame público em igualdade de condições com os demais candidatos, o que abrange: conteúdo, forma de avaliação e critérios de aprovação. Note-se que é exatamente por força do princípio da igualdade que se justifica o tratamento diferenciado - que geralmente consistente em adaptação razoável para que o candidato possa ser submetido à prova -, conferido ao competidor com deficiência. Assim, no que diz respeito às regras para a avaliação desta situação peculiar exige-se uma grande clareza, pois, do contrário poder-se-ia questionar a validade do concurso. Atualmente, entende-se que a aprovação de pessoas com deficiência possa ocorrer se, e somente se, a mesma atingir uma nota mínima estipulada em edital (LARAIA, 2009, p. 147).

É competência comum da União, Estados, Distrito Federal e Municípios “cuidar da saúde e assistência pública, da proteção e garantia das pessoas portadoras de deficiência" (art. 23, inc. II CRFB). Portanto, todas as entidades acima enumeradas possuem um dever, uma obrigação, constitucionalmente imposta no sentido de conceder especial proteção às pessoas com deficiência. Ocorre que, entre os atores sociais envolvidos no processo de inclusão deste grupo específico não se pode perder de vista o papel a ser desenvolvido pela iniciativa privada, em especial pelas empresas, especialmente se considerarmos o reconhecimento da 
função social da empresa. Sendo assim, o Estatuto da Pessoa com Deficiência (Lei 13.146/2015) no caput do art. 34 (re)afirma o direito ao trabalho para este grupo de cidadãos afirmando que a pessoa com deficiência "tem direito ao trabalho de sua livre escolha e aceitação, em ambiente acessível e inclusivo, em igualdade de oportunidades com as demais pessoas". Mas, não para aí, afirmando que as pessoas jurídicas de direito público, privado ou de qualquer outra natureza são obrigadas a garantir ambientes de trabalho acessíveis e inclusivos.

Ora, o que se vê é a nítida intenção do legislador infraconstitucional no sentido de reforçar a busca pela concretização do princípio da isonomia e de não discriminação. Para tanto, impõe-se por intermédio da norma jurídica alguns deveres jurídicos voltados para o respeito às regras de acessibilidade em todas as empresas, sejam elas de natureza pública ou privada, uma vez que se considera "modo de inclusão" a colocação competitiva de pessoas com deficiência, em igualdade de oportunidades com as demais pessoas - art. 37, Lei 13.146/2015. Considerando que exista a imposição de um dever jurídico de observância de regras de acessibilidade a ser observado pelos empregadores, é certo que a recusa quanto à contratação de pessoas com deficiência só possa ocorrer se for justificada sob pena de caracterização de conduta criminalmente típica, conforme previsão contida no art. $8^{\circ}$ da Lei $7.853 / 1999$.

Feitas estas considerações iniciais, é preciso ter em mente quais as três principais modalidades de "garantia de acesso" aos trabalhadores com deficiência, quais sejam: i) colocação competitiva, a ii) colocação seletiva e, por fim, a iii) colocação por conta própria, ou seja trabalhadores autônomos, cooperados ou ainda aqueles que exercem atividades em regime de economia familiar (LARAIA, 2009, p. 151). O recorte teórico adotado para este trabalho privilegia uma abordagem sobre as duas primeiras modalidades (colocação competitiva e a seletiva), porque, em ambas as situações o contrato de trabalho, que geralmente será regido pela CLT, dependerá da análise do papel a ser exercido pelo empregador no sentido de concretizar (ou não) o princípio da igualdade.

Considerando que as finalidades primordiais de políticas públicas de trabalho e emprego sejam, em sua maioria, voltadas para a garantia de acesso e de permanência de trabalhadores com deficiência no mercado formal de trabalho, não há dúvidas quanto à fundamentalidade do papel a ser exercido pelo empresariado no que diz respeito a este processo de inclusão, especialmente se considerarmos o disposto no art. 93 RPS, que permitiu no Brasil a adoção do modelo legal de cotas. 
Este modelo impôs às empresas com 100 (cem) ou mais empregados o dever jurídico de contratação de empregados com deficiência, em percentual variável, entre $2 \%$ a $5 \%$ (dois a cinco por cento), a ser aplicado de forma proporcional em relação ao número de empregados, nos seguintes termos: i) empresas com até 200 (duzentos) empregados possuem o dever de contratar o equivalente a $2 \%$ (dois por cento) deste contingente; ii) será de $3 \%$ (três por cento) nas empresas que tenham em seus quadros funcionais entre 201 e 500 empregados; iii) equivalente a $4 \%$ (quatro por cento) naquelas que apresentam entre 501 a 1.000 empregados e, finalmente, iv) para as empresas que possuam número igual ou superior a 1.001 empregados, o percentual máximo, de 5\% (cinco por cento). Vale ressaltar, cuidou o parágrafo primeiro de garantir que a dispensa do trabalhador reabilitado ou com deficiência, quando contratado por prazo indeterminado, só possa vir a ser considerada válida mediante a contratação de outro empregado em condição semelhante. Assim, é possível reconhecer que se trata de uma modalidade de garantia de emprego a qual, em caso de inobservância por parte da empresa, autoriza o Poder Judiciário, se provocado, a conceder a devida reintegração do empregado com deficiência às funções até então desempenhadas.

Como se vê, uma vez cumprida, a norma em comento tem potencial para se tornar importante instrumento de realização do princípio de igualdade material em nosso ordenamento jurídico. Poucos discordariam da afirmação de que a política de cotas no caso dos trabalhadores com deficiência consista em importante instrumento para a inserção de trabalhadores até então sistematicamente ignorados pelo mercado de trabalho (FONSECA, 2006, p. 264). Todavia, apesar de contar com aproximadamente 25 (vinte e cinco) anos de vigência, o fato é que o artigo 93 RPS, ainda hoje, é motivo de grande controvérsia, sobretudo para os destinatários da norma, o setor empresarial privado. Especificamente sobre o panorama brasileiro de inclusão da pessoa com deficiência no mercado formal de trabalho traçaremos algumas considerações no tópico seguinte.

\subsection{PANORAMA DA INCLUSÃO DE PESSOAS COM DEFICIÊNCIA NO BRASIL}

Questão importante quando se trabalha a noção de pessoa com deficiência é a observação de que existem diferentes tipos de limitação, ou seja, não há como imaginar a existência de homogeneidade entre as características dos membros deste grupo de pessoas. De antemão é possível afirmar que cada uma delas apresentará peculiaridades muito específicas, razão pela qual a generalização não parece ajudar nem no que diz respeito ao processo de 
compreensão do processo de inclusão social das mesmas, nem no de elaboração de ações afirmativas.

Atualmente, o IBGE avalia a deficiência a partir da percepção individual das pessoas entrevistadas, o que se coaduna com a adoção do critério biopsicossocial de avaliação de limitações humanas. Trata-se de orientação internacional sobre o tema e que passou a ser adotada em diversos países. No Brasil o entendimento foi trazido pelo ingresso ao ordenamento jurídico interno da Convenção de Nova York e seu protocolo facultativo (Decreto 6.949/2009) e, apenas consolidada com o Estatuto da Pessoa com Deficiência.

Na prática, isso significa que só será considerada pessoa com deficiência aquela que venha a apresentar um impedimento de longo prazo, que pode ser de natureza física, mental, intelectual ou sensorial, o qual em interação com uma ou mais barreiras, pode vir a obstruir a participação plena e efetiva de tais pessoas na sociedade em igualdade de condições com as demais. Mais do que isso, significa que a avaliação da deficiência, a ser realizada somente em caso de necessidade, devendo ser desenvolvido por equipe multiprofissional e interdisciplinar, conforme previsão contida no artigo $2^{\circ} \S^{\circ}$ do Estatuto da Pessoa com Deficiência.

Segundo dados oficialmente divulgados pelo IBGE, no ano de 2010 existiam 45.606.048 (quarenta e cinco milhões seiscentos e seis mil e quarenta e oito) pessoas com deficiência no Brasil. Em termos estatísticos este número equivale a 23,9\% da população brasileira do período analisado.

Para fins desta pesquisa os dados que mais nos interessam são aqueles que, de alguma forma, podem ser associados à empregabilidade das pessoas com deficiência. Sendo assim, e considerando que por força do art. $7^{\circ}$, inc. XXXIII CRFB exista a proibição do exercício de qualquer trabalho aos menores de dezesseis anos, salvo na condição de aprendiz, a partir de quatorze anos, far-se-á um recorte significativo na análise dos dados estatísticos divulgados para considerar aqueles que se relacionem com a faixa etária das pessoas entre 15(quinze) e 64 (sessenta e quatro) anos de idade - as quais representam o total de 24,94\%, ou seja, aproximadamente um quarto do total de pessoas consideradas "economicamente ativas".

A educação é um direito de todo cidadão brasileiro, situando-se no plano jurídico das garantias constitucionais (art. 205, CRFB). Significa, portanto, que recai também sobre o Poder Público o dever de sua realização, já é compreendida como importante instrumento para preparação de pessoas aptas ao exercício da cidadania, e também no que diz respeito à qualificação para o trabalho. As palavras educação, cidadania e trabalho parecem ser conceitos que em muitos aspectos se relacionam, portanto. E, isto não passou despercebido 
pelo constituinte. Ocorre que, segundo dados do CENSO 2010 apenas 81,7\% das pessoas com deficiência foram indicadas como alfabetizadas em nosso país. Segundo a Secretaria de Direitos Humanos da Presidência da República "as pessoas com deficiência apresentaram taxas de alfabetização menores do que a população total em todas as regiões brasileiras" (OLIVEIRA; SDH-PR; SNDPD-PR, 2012).

Considerando que a equiparação de oportunidades para todos seja corolário do princípio da igualdade material, além de elemento fundamental dos direitos humanos, não parece que às pessoas com deficiência vem sendo assegurada de forma eficiente a garantia constitucional do direito à educação.

Em relação ao nível de instrução, no ano de 2010, chegou-se aos seguintes dados: $14,2 \%$ das pessoas com deficiência apresentava o ensino fundamental completo; $17,7 \%$ o ensino médio e, somente $6,7 \%$ delas possuíam o ensino superior completo. Pessoas com deficiência sem nível de instrução formal representavam, ao momento da pesquisa, $61,1 \%$ da população brasileira (OLIVEIRA; SDH-PR; SNDPD-PR, 2012).

Apesar da exigência da reserva de cotas para trabalhadores com deficiência ou beneficiários reabilitados da Previdência Social a verdade, traduzida em dados estatísticos oficiais, é que ainda hoje a participação deste grupo no mercado de trabalho é muito pouco representativa. Sobre a questão manifestou-se a Secretaria de Direitos Humanos da Presidência da República "apesar da exigência legal de cotas para trabalhadores com deficiência, a participação deles no mercado de trabalho, em 2010, ainda era baixa quando comparada à das pessoas sem deficiência" (OLIVEIRA;PR/SNPD, 2012). Do total de 86,4 milhões de pessoas, de 10 anos ou mais ocupadas, 20,4 milhões eram pessoas com deficiência, ou seja, 23,6\% do total. Em 2010, havia 44.073.377 pessoas com pelo menos uma deficiência e idade ativa, mas 23,7 milhões não estavam ocupadas (OLIVEIRA;PR/SNPD, 2012).

\section{O PRINCÍPIO DA IGUALDADE IMPÕE O DEVER JURÍDICO DE CONTRATAÇÃO DE PESSOAS COM DEFICIÊNCIA PELAS EMPRESAS $\underline{\text { NÃO }}$ OBRIGADAS A OBSERVAR A REGRA CONTIDA ART. 93 RPS?}

Os dados trazidos por esta pesquisa foram extraídos do CENSO, realizado em 2010 pelo IBGE. Tais dados apresentam clareza solar no que diz respeito à demonstração das dificuldades relativas à inserção de pessoas com deficiência no mercado formal de trabalho 
brasileiro. Há uma distorção numérica muito grande quando se faz o cotejo entre os dados relativos às pessoas sem limitações declaradas e aquelas que se autodeclaram com deficiência (uma ou mais formas de limitação). Além disso, não podemos deixar de comentar a existência de diferenciação de acesso de trabalhadores com deficiência relativamente ao gênero, vez que entre elas também parece existir maior facilidade de acesso para o grupo masculino em detrimento do grupo formado apenas por mulheres.

Diante da constatação de que tanto os fundamentos (art. $1^{\circ}$ CRFB) quanto os objetivos da República Federativa do Brasil (art. $3^{\circ} \mathrm{CRFB}$ ) sejam voltados para a busca pela promoção de igualdade, dignidade humana, redução de desigualdades e, como não, para a promoção do desenvolvimento nacional, desponta como sedutora a perspectiva de se extrair do princípio da igualdade a possibilidade de impor aos empregadores com menos de 100 (cem) empregados um dever jurídico de contratação de trabalhadores com deficiência ou beneficiários reabilitados da Previdência Social. Com esta simples medida pode-se imaginar, em um primeiro momento, que mais pessoas com deficiência teria a oportunidade de ingressar no mercado formal de trabalho, e consequentemente seria o princípio da igualdade cumprido de forma ótima.

Será mesmo que esta hipótese é verdadeira? Considerando que o processo de inclusão de trabalhadores com deficiência seja multifacetado, e dependente de outros fatores que vão além da simples colocação no mercado de trabalho, tem-se que a resposta seja negativa. Dados apresentados pela OIT indicavam em 2007 a existência de cerca de 650 (seiscentos e cinquenta) milhões de pessoas com deficiência no mundo (1 em cada 10 pessoas). Do total cerca de 470 (quatrocentos e setenta) milhões já apresentavam idade suficiente para o trabalho, e, efetivamente exerciam atividades remuneradas. Todavia, o que mais chamou atenção nos dados apresentados foi a informação alarmante de que estas, ainda assim, se mantinham em níveis desproporcionais de pobreza e miséria. Portanto, de acordo com a OIT, é possível constatar que existe uma relação estreita entre deficiência e miséria, a qual não está sendo corrigida pelo acesso ao trabalho. Algo a mais deve ser feito para que a inclusão ocorra de forma mais adequada, porque do contrário, estaremos apenas mascarando o problema.

Sendo assim, esta solução não nos parece adequada, o que se justifica, primeiramente, porque não se coaduna com como a estrutura e tampouco com as finalidades que os princípios vêm a apresentar dentro do ordenamento jurídico. E também, porque ao analisarmos o problema da exclusão de trabalhadores é possível observar que outras questões, 
para além da colocação no mercado de trabalho devem ser ponderadas para que se chegue a uma solução ótima para este (triste) problema socioeconômico.

Em que pese a existência de certa controvérsia no que diz respeito à classificação de princípio como espécie de norma jurídica, atualmente, parece ser bem aceita a noção de que as normas jurídicas são o gênero do qual tanto as regras quanto os princípios constituem-se espécie. Contudo, apesar das similitudes inerentes ao fato de pertencerem ao mesmo gênero, isso não quer significar também ambas sejam idênticas em suas características fundamentais. Há características fundamentalmente diferentes entre elas, as quais justificam diferenças na maneira como podem vir a ser aplicadas. Por serem de espécies normativas diferentes é lógico que entre princípios e regras se possam observar incontáveis diferenças, as quais se concentram em dois polos, são eles: i) quanto à estrutura lógica e deontológica; e b) quanto à técnica de aplicação. Sobre eles seguem breves comentários (DE LIMA, 2013, p. 33).

Porque prescreve um valor o princípio da igualdade, quanto ao requisito estrutura lógica e deôntica, classifica-se como um preceito abstrato. Sendo assim, tal como já mencionado no início deste artigo, os princípios "são normas que ordenam que [algo] se realize na maior medida possível, em relação às possibilidades jurídicas e fáticas, como mandados de otimização" (DE LIMA, 2013, p. 33) (ALEXY, 2006, p. 90-91). Em relação à técnica de aplicação é possível dizer que sejam os princípios aplicados em caráter indireto, na medida em que dependem da regra para se concretizarem. Outra característica importante quando se trata de princípios, e com o da isonomia não se passa de outra forma, é a função normogenética que podem vir a exercer. Segundo J. J. Gomes CANOTILHO (p. 1144-1145), seriam os princípios "fundamentos das regras, isto é, são normas que estão na base ou constituem a ratio de regras jurídicas, desempenhando, por isso uma função normativa genética fundamental".

Já a estrutura lógica deôntica de uma regra se consubstancia em um fato hipotético específico. Portanto, deve existir um operador normativo sinalizando a existência de uma proibição, permissão ou ainda de uma imposição (obrigação ou dever) e, desta forma, passam as regras jurídicas a serem observadas em consonância com a regra do "tudo ou nada", exigindo cumprimento pleno (DE LIMA, 2013, p. 33). Como se vê, as regras se dirigem ao caso concreto, e não às abstrações e generalidades características dos princípios. Não é de se estranhar que, quanto à sua origem decorram as regras de imposição do Poder Estatal, o que ocorre a partir do reconhecimento da força normativa de determinados princípios - os quais, tal como já mencionado, encontram sua autoridade na própria base do ordenamento jurídico. 
Pelo exposto, não restam dúvidas acerca da forma de aplicação das regras, posto que só possam ser aplicadas de forma direta (DE LIMA, 2013, p. 34).

Feitas as considerações sobre algumas das características diferenciadoras entre princípio da igualdade e a regra da igualdade far-se-á uma breve análise sobre o art. 93 RPS para verificar se o mesmo constitui-se como princípio ou como regra, e assim tentar encontrar uma solução adequada à problemática que se buscou enfrentar neste artigo. Diz o caput do artigo 93 RPS que a empresa com 100 (cem) ou mais empregados está obrigada a preencher de $2 \%$ (dois por cento) a $5 \%$ (cinco por cento) dos seus cargos com beneficiários reabilitados ou pessoas portadoras de deficiência, habilitadas, na seguinte proporção: I - até 200 empregados: 2\%; I - de 201 a 500: 3\%; III - de 501 a 1.000: 4\%; IV - de 1.001 em diante:5\%.

Não há dúvidas que o conteúdo do art. 93 RPS espelha uma ação afirmativa voltada para a realização do princípio da igualdade em seu viés material. Diz-se isso porque o texto acima transcrito busca garantir por intermédio da reserva de vagas para pessoas com deficiência a ampliação do acesso, e, em alguma medida, a garantia de permanência de pessoas deste grupo de cidadãos no mercado formal de trabalho. Trata-se então de uma norma jurídica voltada para a realização de objetivos da República Federativa do Brasil (art. $3^{\circ}$ CRFB), mais especificamente a noção de necessidade de erradicação da pobreza e desigualdades sociais e regionais. Mas, não só isso, porque também guarda relação com a concretização de um dos fundamentos desta República, qual seja a dignidade da pessoa humana (art. $1^{\circ}$, III CRFB). Todavia, não podemos deixar de observar que é uma norma bastante específica, pois, ainda que voltada para a coletividade de pessoas com deficiência ela não se presta a corrigir toda e qualquer distorção social causada por discriminação, mas sim, aquelas que acabam de alguma maneira por obstar o acesso e a permanência de trabalhadores com deficiência no mercado de trabalho.

Quando se afirma “a empresa com 100 (cem) ou mais empregados" esta é uma hipótese fática para a qual o legislador atrelou como consequência jurídica a imputação de um dever (operador normativo) de que as mesmas venham a "preencher de $2 \%$ (dois por cento) a $5 \%$ (cinco por cento) dos seus cargos com beneficiários reabilitados ou pessoas portadoras de deficiência, habilitadas" de maneira proporcional ao número de empregados que possua o empregador. Não há dúvidas de que estamos diante da demonstração da estrutura de uma regra de natureza jurídica.

Assim, a norma jurídica contida no art. 93 RPS deve ser observada como uma regra jurídica, e não como um princípio. Vale dizer, é regra que se origina a partir do caráter 
normogenético do princípio da isonomia, e que, portanto, deve ter por escopo basilar assegurar parte de seu conteúdo valorativo, mas com este não pode ser confundido, tendo em vista que se sujeita à regra do "tudo ou nada". É considerado "cumprido" quando observado em sua totalidade e, "descumprido" quando observado total ou apenas parcialmente violado. Não há, portanto, como ser observada em caráter "ótimo" ou de acordo como aquilo que seja considerado o "máximo jurídico e faticamente possível”, porque não se trata de um mandado de otimização.

No caso do art. 93 RPS é importante frisar ainda a possibilidade de imposição de sanção, na forma de multa, pelo descumprimento da prescrição contida na regra. Trata-se da previsão contida no art. 133 RPS, o qual é atualmente regulamentado pelo art. $8^{\circ}$ inc. IV da Portaria Interministerial MTPS $\mathrm{n}^{\mathrm{o}} 1 / 2016$, que impõe o pagamento de multa pela inobservância da norma, que pode variar, conforme a gravidade da infração, de R $\$ 2.143,04$ (dois mil cento e quarenta e três reais e quatro centavos) a $\mathrm{R} \$ 214.301,53$ (duzentos e catorze mil trezentos e um reais e cinquenta e três centavos). Vale dizer, segundo Norberto BOBBIO (2005, p. 153), a sanção seria um “expediente através do qual se busca, em um sistema normativo, salvaguardar a lei da erosão das ações contrárias”. Ora, o que é o art. 93 RPS senão a tentativa do legislador de salvaguardar a realização da regra de igualdade, a qual, em última análise, é ferramenta que visa assegurar a realização do princípio da igualdade?

$\mathrm{O}$ art. 93 RPS, na condição de regra jurídica, impõe um operador normativo de "dever" ou "obrigação" destinando-se apenas para as empresas que possuam 100 (cem) ou mais funcionários. Ora, se uma regra exige cumprimento pleno, sob pena de ser considerada descumprida, não parece razoável a tentativa de praeter legem se ampliar os destinatários a quem esta norma-regra se destina, ainda que se defenda este posicionamento com fundamento na norma-princípio que ensejou a criação da regra - no caso em análise a igualdade.

Não há dúvidas que o princípio da isonomia apresenta um contorno jurídico extremamente complexo. Mas, não se pode perder de vista que esta norma deve servir como "um instrumento constitucional de preservação de si própria" (GRAU, 2008, p. 167). Em outras palavras, a defesa da igualdade material não pode justificar violações à igualdade formal para assim permitir tamanha inovação no ordenamento jurídico, a ponto de promover a imposição de um dever jurídico para aqueles a quem a lei nada impôs.

O que se quer dizer com isso é no sentido de que a discriminação positiva tutelada pelo artigo 93 RPS não pode justificar, sem alteração legislativa adequada, a ampliação na 
interpretação dada à regra para autorizar a imposição de tal para destinatários que não constam expressamente de seu enunciado. Portanto, só podemos fazer uma leitura adequada da isonomia quando partimos da conexão de seus vieses, material e formal. Um sem o outro não nos podem conduzir a um caminho seguro, podendo ser as condutas daí provenientes de "injustas".

\section{CONSIDERAÇÕES FINAIS}

A resposta ao questionamento que motivou esta pesquisa não é de fácil obtenção. Em primeiro lugar, porque é tentador, especialmente diante do triste quadro de exclusão social a que diariamente pessoas com deficiência são expostas, afirmar que "sim, seria aceitável que decorresse da interpretação constitucional do princípio da isonomia um dever de contratação de pessoas com deficiência também por parte das empresas que não estão obrigadas ao cumprimento do art. 93 RPS". E, em segundo momento, porque a vontade de reverter esta situação é tamanha que podemos abandonar, por um período, a logicidade do próprio sistema em que esta regra jurídica encontra-se inserida. Todavia, não podemos deixar que no afã de consertar as coisas que nos desagradam, comecemos a ignorar uma das características fundamentais do ordenamento jurídico, que é a sistematização e a logicidade.

O princípio da igualdade atua no sentido de nos compelir a preservar e a reconhecer a igualdade enquanto aptidão ou possibilidade virtual de cada um, e de todos. Sendo assim, todos passam a merecer tratamento igualitário nos termos da CRFB. Mas, é também este documento que reconhece situações em que só possa ser considerada igual a oportunidade concedida quando alguns "ajustes" ou "correções" sejam feitas, autorizando assim a criação das ações afirmativas. As ações afirmativas, por sua vez, nada mais são do que políticas públicas voltadas para a correção de distorções socioeconômicas que venham a ser observadas no caso concreto. Este princípio por intermédio das ações afirmativas passa a se individualizar, em conformidade com as peculiaridades do caso que pretende corrigir, para se transformar em regra jurídica.

Assim se passa com o art. 93 da RPS, que é ação afirmativa voltada para inclusão de trabalhadores com deficiência no mercado formal de trabalho. A reserva de cotas garante o acesso e a permanência de tal grupo em empresas, vem se demonstrando como fator essencial 
para a promoção da dignidade humana, e também, como não poderia ser diferente, para a realização do princípio da igualdade.

É notório que a ação afirmativa, por si só, não tem o condão de resolver este (grave) problema social. Vale dizer, quando examinamos a pequena participação de trabalhadores com deficiência no mercado de trabalho brasileiro devemos atentar para uma verdadeira confluência de fatores que colocam este grupo à margem da sociedade, entre os quais, a título meramente exemplificativo, citaremos a ausência de acessibilidade em espaços públicos e privados, barreiras comportamentais (discriminação e preconceitos) e baixo grau de escolaridade. Pelo exposto, parece que a fraca participação de trabalhadores com deficiência no mercado de trabalho seja justificável não apenas pela ausência de legislação (mais) protetiva, mas sobretudo pela "carência de ações, estímulos e instituições que viabilizem, de forma concreta, a formação, a habilitação, a reabilitação (quando necessário) e a inserção de pessoas com deficiência no mercado formal de trabalho.

Ora, se o princípio da igualdade autorizasse a criação do dever jurídico de contratação de pessoas com deficiência para as empresas não enquadradas na norma contida no art. 93 RPS tal interpretação seria, a um só tempo desarrazoada e abusiva e, ainda pior, muito provavelmente permaneceria sendo ineficaz do ponto de vista social. Seria desarrazoada e abusiva porque contraria toda e qualquer interpretação razoável que se possa fazer acerca da diferenciação estrutural e de alcance entre regras e princípios. Pois, uma vez estruturada como regra submete-se a necessidade de plena observância, sob pena de caracterização de descumprimento. Não pode ser realizada como se mandamento de otimização fosse, pois esta é característica inerente à estrutura lógico deôntica dos princípios.

A ineficácia do ponto de vista social decorre da constatação de que esta alteração na forma de se interpretar a regra não parece dar conta de resolver o problema da baixa qualificação dos profissionais com deficiência. Considerando que um dos fatores de maior reclamação ao cumprimento da regra em comento por parte do empresariado seja o de que há grande dificuldade de contratação de tais profissionais em decorrência da baixa qualificação profissional que muitos deles apresentam, não parece que, por si só, tal alteração pudesse propiciar o aumento da qualificação profissional deste grupo.

O problema da inclusão de trabalhadores com deficiência no mercado formal de trabalho brasileiro, portanto, parece ser apenas uma parte do problema relativo à integração de tal grupo na vida em sociedade. Muitos fatores, tais como educação básica, qualificação profissional, e acesso e acessibilidade (incluindo questões relativas à comunicação) estão a ele 
diretamente relacionados. Portanto, ao tentarmos reduzir a solução deste problema apenas a questão de aumento da colocação de trabalhadores no mercado de trabalho, ainda que em nome do princípio da igualdade, correremos o risco de permanecer defendendo nobres declarações de direitos, com pouca ou nenhuma efetividade no que diz respeito à possibilidade de promover mudanças positivas na sociedade contemporânea.

\section{REFERÊNCIAS BIBLIOGRÁFICAS}

ALEXY, Robert. Teoria dos Direitos Fundamentais. Trad. Virgílio Afonso da Silva. $5^{\mathrm{a}}$ ed.. São Paulo: Malheiros, 2006.

BERTONCINI, Mateus. A função da empresa na implementação dos direitos da criança e do adolescente: globalização e trabalho infantil. Curitiba: Instituto Memória, 2014.

BOBBIO, Norberto. Teoria da Norma Jurídica. Trad. Fernando Pavan Baptista e Ariani Bueno Sudatti. 3. ed.. Bauru, SP: EDIPRO, 2005.

CAnotilho, J. J. Gomes. Direito Constitucional e Teoria da Constituição. $5^{\text {a }}$ edição. Coimbra: Almedina.

DE LIMA, Francisco Meton Marques. Os princípios do direito do trabalho na lei e na jurisprudência. 3. ed.. São Paulo: LTr, 2013.

FONSECA, Ricardo Tadeu Marques da. O trabalho da pessoa com deficiência e a lapidação dos direitos humanos: o direito do trabalho, uma ação afirmativa. $327 \mathrm{f}$. Dissertação (Mestrado em Direito). Universidade Federal do Paraná, Curitiba, 2006. Disponível em: http://dspace.c3sl.ufpr.br/dspace/bitstream/handle/1884/2423/?sequence=2 Acesso em 10.out.2015, às $12 \mathrm{~h} 11 \mathrm{~min}$.

GONZAGA, Álvaro de Azevedo. O princípio da Igualdade: é juridicamente possível no ordenamento jurídico existirem leis discriminatórias? Revista Scientia FAER. Olímpia, São Paulo, Vol. 1, Ano 1, p. 1-10, $2^{\circ}$ Semestre, 2009. Disponível em: http://www.faer.edu.br/revistafaer/artigos/edicao1/110_alvaro_de_azevedo_gonzaga\%5B1\%5 D.pdf> Acesso em: 16 Jul.2016 às 15h04min.

GRAU, Eros Roberto. O direito posto e o direito pressuposto. 7. ed.. São Paulo: Malheiros, 2008.

LARAIA, Maria Ivone Fortunato. A pessoa com deficiência e o direito ao trabalho. 189 f. (Mestrado em Direito), Pontifícia Universidade Católica de São Paulo - PUC-SP, 2009. Disponível em: http://www.dominiopublico.gov.br/download/teste/arqs/cp121701.pdf Acesso em: 17h58min às $19 \mathrm{~h} 58 \mathrm{~min}$.

MELLO, Celso Antônio Bandeira de. Conteúdo jurídico do princípio da igualdade. 3. ed.. Malheiros: São Paulo, 1995. 
MENEZES, Paulo Lucena de. A ação afirmativa (affirmative action) no direito norteamericano. São Paulo: Revista dos Tribunais, 2001.

MOEHLECKE, Sabrina. Ação afirmativa: História e Debates no Brasil. Cadernos de Pesquisa. n.117, p. 197-217, Novembro, 2002. Disponível em: http://www.scielo.br/pdf/cp/n117/15559.pdf Acesso em: 16 Jul.2016 às 22h51min.

OLIVEIRA, Luiza Maria Borges; SECRETARIA DE DIREITOS HUMANOS DA PRESIDÊNCIA DA REPÚBLICA; SECRETARIA NACIONAL DA PROMOÇÃO DOS DIREITOS DAS PESSOAS COM DEFICIÊNCIA NA PRESIDÊNCIA DA REPÚBLICA. Cartilha do Censo 2010: Direitos das pessoas com deficiência. Coordenação-Geral do Sistema de Informações sobre a Pessoa com Deficiência, Brasília: SDH-PR/SNPD, 2012. Disponível em: http://www.pessoacomdeficiencia.gov.br/app/sites/default/files/publicacoes/cartilha-censo2010-pessoas-com-deficienciareduzido.pdf Acesso em: 20 dez. 2015.

PASTORE, José. Oportunidades de trabalho para portadores de deficiência. São Paulo: LTr, 2000.

ROCHA, Carmen Lúcia Antunes. Ação Afirmativa: O conteúdo democrático do princípio da igualdade jurídica. Revista de informação legislativa. v. 33., n. 131, p. 283-295, jul./set. 1996. Disponível em: http://www2.senado.leg.br/bdsf/item/id/176462 Acesso em 30 jun.2016 às 20h12min.

SZUPSZYNSKI, Vanessa Del Rio. Direito à ação afirmativa: conceito, validade e condições necessárias para realização em matéria de emprego e ocupação. São Paulo: LTr, 2014. 